\title{
EvaluACIÓN DE LA CAPACIDAD DE INHIBICIÓN DE HEMÓLISIS OXIDATIVA Y ACTIVIDAD ANTIMICROBIANA DE FRACCIONES PEPTÍDICAS OBTENIDAS DE LA HIDRÓLISIS DE PROTEÍNAS DE HUEVO, LECHE Y SOYA USANDO PROTEASAS EXTRAÍDAS DE Bromelia pinguin Y Bromelia karatas
}

\author{
Selene Aguilera-Aguirre', Libier Meza-Espinoza', \\ Adrián Hernández-Mendoza², Belinda Vallejo-Córdoba², \\ Aarón F. González-Córdova ${ }^{2}$ y Efigenia Montalvo-González ${ }^{1 a}$ \\ ${ }^{1}$ Laboratorio Integral de Investigación en Alimentos, Tecnológico Nacional de México- \\ Instituto Tecnológico de Tepic. Av. Tecnológico \# 2595, Tepic 63175, Nayarit, México, \\ ${ }^{2}$ Centro de Investigación en Alimentación y Desarrollo A.C., Hermosillo, Sonora, México. \\ E-mail: ${ }^{1 a}$ emontalvo@ittepic.edu.mx
}

\begin{abstract}
Resumen
Los hidrolizados proteínicos son una fuente de péptidos bioactivos (PB) y estos compuestos pueden ejercer un papel importante en la salud humana debido a sus diferentes acividades biológicas. El uso de proteasas de origen vegetal es una alternativa potencial para producir PB. El objetivo de este trabajo fue evaluar la capacidad de inhibición de la hemólisis oxidativa $(\mathrm{IHO})$ y actividad antimicrobiana de hidrolizados y fracciones peptídicas obtenidas de la hidrólisis de proteínas de huevo (ovoalbúmina), leche y soya, con proteasas extraídas de frutos de Bromelia pinguin y Bromelia karatas. En general, todos los hidrolizados y fracciones peptídicas presentaron una alta IHO, siendo la fracción peptídica de $\leq 1 \mathrm{kDa}$, obtenida de la hidrólisis de ovoalbúmina con proteasas de B. karatas, la que presentó mayor actividad (98.19\%). En contraste, ninguno de los hidrolizados registró actividad antimicrobiana, mientras que las fracciones peptídicas $(\leq 5, \leq 10$ y $\leq 30 \mathrm{kDa}$ ), obtenidas de la hidrólisis de leche con proteasas de B. pinguin, mostraron la mayor actividad antimicrobina (22.26-23.79\% de inhibición), contra Listeria innocua. Los resultados resaltan el potencial de las proteasas de B. pinguin y B. karatas para hidrolizar proteínas de diferentes alimentos y generar hidrolizados y PB con alta actividad antioxidante.
\end{abstract}

Palabras Clave: inhibición hemolítica oxidativa, actividad antimicrobiana, hidrolizada, péptidos bioactivos.

Evaluation of oxidative hemolytic inhibition capacity and antimicrobial activity of peptide fractions from egg, milk and soy protein hydrolysis using Bromelia pinguin and Bromelia karatas derived proteases

\begin{abstract}
Protein hydrolysates are a source of bioactive peptides (BP). They can exert an important role in human health due to their different biological activities. The use of plant proteases is a potential alternative to produce BP. The aim of this work was to evaluate the oxidative hemolytic inhibition capacity (OHI) and antimicrobial activity of hydrolysates and peptide fractions from egg, milk and soy protein hydrolysis with proteases extracted from Bromelia pinguin and Bromelia karatas fruits. In general, all hydrolysates and peptide fractions presented a high OHI, being the peptide fraction of $\leq 1 \mathrm{kDa}$ from ovalbumin protein hydrolysis with B. karatas proteases that had the greater OHI (98.19\%). In contrast, hydrolysates did not register antimicrobial activity, while peptide fractions ( $\leq 5, \leq 10$ y $\leq 30 \mathrm{kDa}$ ), from milk hydrolysis with B. pinguin proteases showed the highest antimicrobial activity against Listeria innocua $(22.26-23.79 \%$ of inhibition). The results highlight the potential of $B$. pinguin and B. karatas proteases to hidrolize proteins from different foods, as well as to produce hydrolysates and BP, with high oxidative hemolytic inhibition capacity.
\end{abstract}

Key Words: oxidative hemolytic inhibition, antimicrobial activity, hydrolysates, peptides.

Nota: Artículo recibido el 26 de octubre de 2017 y aceptado el 26 de abril de 2018. 


\section{INTRODUCCIÓN}

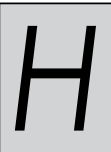

oy en día las proteínas alimentarias han recibido una atención especial, ya que algunos fragmentos de estas proteínas pueden liberarse por hidrólisis y exhibir actividad biológica. Estos fragmentos denominados péptidos bioactivos (BP), generalmente se generan in vivo por la acción de las enzimas gastrointestinales, pero también pueden obtenerse in vitro con proteasas específicas (Sila \& Bougatef, 2016).

Las proteasas específicas más utilizadas para generar PB son las microbianas; sin embargo, el uso de proteasas vegetales en la hidrólisis de proteínas se ha incrementado en los últimos años debido a su estabilidad en un amplio rango de $\mathrm{pH}$ y temperatura (Moreno-Hernández et al., 2017). Las proteasas extraídas de frutos de Bromelia karatas (B. karatas) y Bromelia pinguin (B. pinguin) no han sido estudiadas para generar PB; no obstante, de acuerdo a estudios previos, estas proteasas presentan una alta actividad proteolítica, con un grado de hidrólisis de $73-80 \%$ (Meza-Espinoza et al., 2017) por lo tanto, son potenciales para la generación de $\mathrm{PB}$.

Los PB juegan un papel importante en la regulación y modulación metabólica y se pueden usar como potencial nutracéutico y como ingredientes de alimentos funcionales. Las actividades biológicas más estudiadas de los PB son la actividad antimicrobiana y la actividad antioxidante (Przybylsky, Firdaous, Châtaigné, Dhulster \& Nedjar, 2016). Los PB con actividad antimicrobiana (AMPs por sus siglas en inglés) presentan mecanismos de acción complejos y están relacionados con la interacción que tienen con la membrana del patógeno o con sus componentes internos, afectando la replicación del DNA y la síntesis de proteínas causando así la muerte del microorganismo (Reinhardt \& Neundfor, 2016). Zhang et al. (2017) reportaron que el péptido Casein201, inhibió el crecimiento de Staphylococcus aureus y Yersinia enterocolitica, a través de la desintegración de estructuras citoplásmicas y alteraciones de la envoltura celular bacteriana. Por otra parte, la actividad antioxidante de los PB, se ha asociado a la presencia de aminoácidos como cisteína, metionina, tirosina, fenilalanina, triptófano, prolina y lisina entre otros; que permiten una buena acción antiradical y quelante, debido a que estos aminoácidos son capaces de donar electrones o formar complejos con iones metálicos (Xiong, 2010).

Los métodos in vitro más usados para medir la actividad antioxidante son atrapamiento del radical ABTS $\left(2,2^{\prime}\right.$-azinobis3-etilbenzothiazolina-6-ácido sulfónico), poder antioxidante de reducción de hierro (FRAP por su siglas en inglés) y capacidad de absorbancia del radical oxígeno (ORAC por sus siglas en inglés) (Kumar, Chatli, Singh, Mehta \& Kumar, 2016); sin embargo, Takebayashi, Chen \& Tai (2010) mencionan que uno de los mejores ensayos para medir la actividad antioxidante de los PB, es a través de la inhibición de la hemólisis oxidativa, siendo un buen modelo experimental debido a que se puede medir el porcentaje de inhibición del daño de las membranas de los eritrocitos inducido por radicales libres, emulando procesos que ocurren en células humanas.

Debido a que los PB se siguen evaluando como una alternativa potencial de consumo tanto como aditivos alimentarios o como de consumo directo, adicionados a la dieta para combatir enfermedades (Sadredinamin, Mehrnejad, Hosseini \& Doustdar, 2016); y a que es necesario investigar nuevas proteasas vegetales como una alternativa potencial para generar PB, el objetivo de este trabajo fue evaluar la capacidad de inhibición de la hemólisis oxidativa y actividad antimicrobiana de hidrolizados y fracciones péptidícas obtenidos de la hidrólisis de proteínas de huevo (ovoalbúmina), leche y soya usando proteasas extraídas de frutos de $B$. pinguin y $B$. karatas.

\section{MAteriales y métodos Material vegetal}

Se recolectaron frutos de color amarillo considerados como frutos maduros, de las especies silvestres de $B$. pinguin y $B$. karatas en Santiago Ixcuintla, Nayarit, México. Las características fisicoquímicas de la pulpa de $B$. pinguin y $B$. karatas fueron las siguientes: $\mathrm{pH}, 3.57 \pm 0.04$ y $3.11 \pm 0.04$; sólidos solubles, $12.35 \pm 0.12$ y $16.64 \pm 0.14^{\circ} \mathrm{Bx}$; Acidez titulable, $2.45 \pm 0.02 \%$ y $3.33 \pm 0.35 \%$; proteína total, $8.14 \pm 0.05 \%$ y $7.22 \pm 0.03 \%$, respectivamente. Se eliminó la cáscara y semillas del fruto y la pulpa se almacenó a $-80{ }^{\circ} \mathrm{C}$ (Forma Scientific modelo 926, Ohaio, USA.) hasta su uso. Los concentrados de proteína de soya y leche fueron obtenidos de Nestlé S.A. de C.V.; mientras que la proteína de huevo (ovoalbúmina) fue adquirida en HYCEL de México S.A de C.V.

\section{Extracción de proteasas}

Para la extracción de proteasas de cada especie vegetal, se siguió la metodología descrita por Meza-Espinoza et al. (2017). El extracto crudo enzimático (CE) de B. karatas se obtuvo con una solución amortiguadora de fosfato-cisteína (solución de fosfato $0.1 \mathrm{M}$, EDTA $5 \mathrm{mM}$ y cisteína $5 \mathrm{mM}$ ajustada a pH 6.1); mientras que el CE de B. pinguin se obtuvo con una solución amortiguadora de sulfuro de sodio $\left(\mathrm{Na}_{2} \mathrm{~S} 2\right.$ $\mathrm{mM} \mathrm{y} \mathrm{H}_{2} \mathrm{SO}_{4} 0.2 \mathrm{mM}$, ajustado a $\mathrm{pH} 6.1$ ). Todas las soluciones de extracción se mantuvieron en refrigeración $\left(4^{\circ} \mathrm{C}\right)$. Se usaron $50 \mathrm{~g}$ de pulpa congelada $\left(-80^{\circ} \mathrm{C}\right)$ de cada especie vegetal; se agregaron $250 \mathrm{~mL}(1: 5 \mathrm{p} / \mathrm{v})$ de cada solución de extracción a temperatura ambiente y se dejó 10 min para descongelación completa. Las mezclas se homogeneizaron, se filtraron y luego se centrifugaron (Hermle Z306, Wehingen, Alemania) a 6,000xg durante $15 \mathrm{~min}$ a $4{ }^{\circ} \mathrm{C}$. Los sobrenadantes (CE) se precipitaron con acetona fría $\left(-20^{\circ} \mathrm{C}\right)$ en una relación de 1:1 (v/v) añadiendo lentamente el disolvente. La mezcla se mantuvo durante $1 \mathrm{~h}$ a $-20{ }^{\circ} \mathrm{C}$. El primer precipitado proteínico se separaró por decantación y se eliminó. A cada sobrenadante se añadieron dos volúmenes de acetona fría, respecto al volumen del sobrenadante y se 
mantuvieron durante $1 \mathrm{~h} \mathrm{a}-20^{\circ} \mathrm{C}$. Los precipitados se separaron por decantación y se centrifugaron a 6,000 xg durante $10 \mathrm{~min}$ a $4{ }^{\circ} \mathrm{C}$. Los precipitados fueron considerados como proteasas parcialmente purificadas. Las proteasas obtenidas se liofilizaron usando liofilizador LABCONCO (Modelo 77522020, Kansas, USA) y se almacenaron a $-80{ }^{\circ} \mathrm{C}$ hasta su análisis.

\section{Obtención de hidrolizados}

Se usó la metodología propuesta por Natalucci, Brullo, López, Hilal \& Caffini (1996). Se prepararon soluciones de ovoalbúmina, leche y soya $(10 \mathrm{~g} / \mathrm{L})$ con una solución amortiguadora de fosfato $0.1 \mathrm{M}$ a pH 7.0 (SAF); luego se calentaron a $90{ }^{\circ} \mathrm{C}$ en un baño de agua durante 20 min y se centrifugaron a $12,000 \mathrm{xg}$ durante $10 \mathrm{~min}$. Los sobrenadantes se usaron como sustratos. La obtención de los hidrolizados se llevó a cabo con muestras de $250 \mathrm{~mL}$ de cada solución y $25 \mathrm{~mL}$ de proteasas liofilizadas (resuspendidas con amortiguador de fosfatos $\mathrm{pH}$ 7.0, para tener una concentración de $1.7 \mathrm{mg}$ de proteasas liofilizadas $/ \mathrm{mL}$ de solución). La mezcla se incubó a $60{ }^{\circ} \mathrm{C}$ durante 30 , 60 y $120 \mathrm{~min}$. La hidrólisis se detuvo colocando la mezcla de reacción a ebullición durante $10 \mathrm{~min}$. Las muestras se enfriaron a temperatura ambiente y se centrifugaron a 16,000 $x g$ a $4{ }^{\circ} \mathrm{C}$ durante $10 \mathrm{~min}$. Los sobrenadantes se liofilizaron y se almacenaron a $-80{ }^{\circ} \mathrm{C}$ hasta su uso.

\section{Separación de fracciones peptídicas}

La separación de péptidos se llevó a cabo de hidrolizados obtenidos durante 60 min de hidrólisis, usando la metodología de ultrafiltración por membrans (Cho, Unklesbay, Hsieh \& Clarke, 2004). Se utilizó una unidad de ultrafiltración (Millipore mini system 8,050, Bedford, MA) con membranas de tamaño de corte de 30, 10, 5 y $1 \mathrm{kDa}$. El sistema de filtración se trabajó a $1,379 \mathrm{kPa}$ de presión y $4{ }^{\circ} \mathrm{C}$. Se obtuvieron cuatro fracciones peptídicas: $\leq 30 \mathrm{kDa}, \leq 10 \mathrm{kDa}, \leq 5 \mathrm{kDa} \mathrm{y} \leq 1 \mathrm{kDa}$. Las fracciones peptídicas se liofilizaron y se almacenaron a $-80{ }^{\circ} \mathrm{C}$ hasta su análisis.

\section{Determinación de actividad proteolítica}

La metodología propuesta por Natalucci, Brullo, López, Hilal \& Caffini (1996) con algunas modificaciones de Meza-Espinoza et al. (2017) se siguieron para medir la actividad proteolítica de las proteasas parcialmente purificadas. Se utilizó $1 \mathrm{~mL}$ de solución de ovoalbúmina $(10 \mathrm{mg} / \mathrm{mL})$ como sustrato. Luego, se añadieron al sustrato $200 \mu \mathrm{L}(2.6 \mathrm{mg}$ de muestra liofilizada en $1.5 \mathrm{~mL}$ de tampón de fosfato a pH 7.0 o una concentración de $1.7 \mathrm{~g} / \mathrm{mL}$ ) de proteasa. La mezcla de reacción se incubó durante 20 minutos a $37^{\circ} \mathrm{C}$, luego se añadieron $1.8 \mathrm{~mL}$ de ácido tricloroacético $(50 \mathrm{~g} / \mathrm{L})$ para detener la reacción. Las muestras se enfriaron y centrifugaron a $14,000 \mathrm{xg} \mathrm{a} 4{ }^{\circ} \mathrm{C}$ durante $10 \mathrm{~min}$ y se midió la absorbancia del sobrenadante a $280 \mathrm{~nm}$. Se preparó un blanco añadiendo TCA a la mezcla de reacción antes de la incubación de la enzima con el sustrato. Una unidad de actividad (U) se definió como los milimoles de tirosina por minuto bajo las condiciones de ensayo anteriores. La actividad específica
(EA) se calculó como U/mg de proteína. La proteína total se midió con el método de Bradford (Bradford, 1976), mezclando $2.6 \mathrm{mg}$ del liofilizado proteíco con $1.5 \mathrm{~mL}$ de tampón de fosfato (0.1 M, pH 7.0). Luego, a $200 \mu \mathrm{L}$ de la mezcla se añadieron $600 \mu \mathrm{L}$ del reactivo Bradford y se incubaron a temperatura ambiente durante $10 \mathrm{~min}$. La absorbancia se midió a $595 \mathrm{~nm}$ (Jenway 6705, Cole-Parmer Instrument Co., Felsted, Reino Unido) y para calular el contenido de proteína se realizó una curva estándar de albúmina de suero bovino.

\section{Inhibición de hemólisis oxidativa (IHO)}

El ensayo de IHO, se realizó como lo describe Takebayashi, Chen \& Tai (2010). Para la obtención de eritrocitos, se utilizaron $5 \mathrm{~mL}$ de sangre extraída de cada uno de tres individuos aparentemente sanos. La muestra de sangre se guardó en tubos BD vacutainer con EDTA K2 como anticoagulante. La sangre $(2 \mathrm{~mL})$ se centrifugó a $2,500 x g$ por $5 \mathrm{~min} \mathrm{a} 4{ }^{\circ} \mathrm{C} \mathrm{y} \mathrm{el}$ sobrenadante fue desechado. Las células sanguíneas aisladas (eritrocitos) fueron lavadas con $\operatorname{SAF}(1: 1, \mathrm{v} / \mathrm{v})$, y se centrifugó a 2,000 xg por $10 \mathrm{~min}$ a $4{ }^{\circ} \mathrm{C}$, nuevamente. Este proceso de lavado se repitió dos veces más. Los eritrocitos se diluyeron con SAF, 10 veces de su volumen original y de esta solución se obtuvo una dilución correspondiente al $1 \%$ del volumen original. Se mezclaron $150 \mu \mathrm{L}$ de eritrocitos con $150 \mu \mathrm{L}$ de muestra $(0.15 \mathrm{mg} / \mathrm{mL}$ de hidrolizados o fracción peptídica), se incubó por $1 \mathrm{~min}$ a $37^{\circ} \mathrm{C}$ y después se agregaron $150 \mu \mathrm{L}$ de dihidrocloruro de 2,2' - azobis (2-amidinopropano) (AAPH, por sus siglas en inglés) a $400 \mathrm{mM}$. La mezcla se agitó suavemente, posteriormente se incubó por $2 \mathrm{~h}$ a $37^{\circ} \mathrm{C}$ y se centrifugó a $10,000 x g$ por $2 \mathrm{~min}$ y la absorbancia del sobrenadante fue registrada a $524 \mathrm{~nm}$ en un lector de microplacas (SpectraMax M3 Series Multi-Mode Microplate Readers, Molecular Devices, Sunnyvale, CA, USA). Se usó un control positivo, el cual fue preparado mezclando $150 \mu \mathrm{L}$ de eritrocitos, $150 \mu \mathrm{L}$ de $\mathrm{SAF}$ y $150 \mu \mathrm{L}$ de $\mathrm{AAPH}$; mientras que el control negativo fue preparado con $150 \mu \mathrm{L}$ de eritrocitos, $150 \mu \mathrm{L}$ de SAF y $150 \mu \mathrm{L}$ de muestra. La IHO se expresó en porcentaje de inhibición y se calculó con la ecuación (1):

Porcentaje de inhibición $(\%)=100-\left(\frac{A b s_{m}-A b s_{c n}}{A b s_{c p}-A b s_{c n}} \times 100\right)$

En donde: $\mathrm{Abs}_{\mathrm{m}}=\mathrm{Absorb}$ ancia de la muestra; $\mathrm{Abs}_{\mathrm{cp}}=\mathrm{Absorbancia}$ del control positivo; $\mathrm{Abs}_{\mathrm{cn}}=$ Absorbancia del control negativo.

\section{Actividad antimicrobiana}

Las cepas utilizadas pertenencen al cepario del Laboratorio de Química y Biotecnología de Productos Lácteos, del Centro de Investigación en Alimentación y Desarrollo A.C., dichas cepas inlcuyen Escherichia coli ATCC25922, Salmonella Typhimurium ATCC14028, Salmonella entérica serotipo Choleraesuis ATCC10708, Staphylococcus aureus ATCC29213b y Listeria inoccua ATCC33090. Las bacterias 
fueron activadas y propagadas inoculando caldo de infusión de cerebro corazón (BHI, por sus siglas en inglés) e incubando a $37^{\circ} \mathrm{C}$ por $10 \mathrm{~h}$. Una vez transcurrido el periodo de incubación, las bacterias fueron recuperadas por centrifugación $(5,000 \mathrm{xg}$ por $10 \mathrm{~min}$ ), lavadas 2 veces con $5 \mathrm{~mL}$ de SAF y resuspendidas en la misma solución hasta alcanzar una $\mathrm{DO}_{600 \mathrm{~nm}}=0.8$ (No. Células $24 \times 10^{8} / \mathrm{mL}$ ).

Para la determinación de la actividad antimicrobiana de los hidrolizados y fracciones peptídicas se usó el método descrito por Eloff (1998). Los hidrolizados y fracciones peptídicas liofilizadas se redisolvieron en SAF a una concentración de $(0.15 \mathrm{mg} / \mathrm{mL})$. Se usó un control negativo $(80 \mu \mathrm{L}$ de agua destilada estéril y $100 \mu \mathrm{L}$ de BHI), un control positivo $(40 \mu \mathrm{L}$ de agua destilada estéril, $40 \mu \mathrm{L}$ de solución bacteriana ajustada y $100 \mu \mathrm{LdeBHI})$ y las muestras $(40 \mu \mathrm{L}$ de solución de hidrolizados o fracciones peptídicas con $40 \mu \mathrm{L}$ de solución bacteriana y 100 $\mu \mathrm{L}$ de caldo BHI). Las mezclas se incubaron a $37^{\circ} \mathrm{C}$ por $10 \mathrm{~h}$ y después de ese tiempo se midió la absorbancia a $600 \mathrm{~nm}$. Se calculó el porcentaje de supervivencia (Ecuación 2) y después se calculó el porcentaje de inhibición (100 - \% de supervivencia) (Aguilar-Toalá et al., 2017).

Porcentaje de supervivencia $(\%)=\left(\frac{D O_{m}}{D O_{c p}-D O_{c n}}\right) \times 100$

$\mathrm{DO}_{\mathrm{m}}=$ Densidad óptica de la muestra con hidrolizados o fracciones peptídicas; $\mathrm{DO}_{\mathrm{cp}}=$ Densidad óptica del control positivo; $\mathrm{DO}_{\mathrm{cn}}=$ Densidad óptica del control negativo.

\section{Análisis estadístico}

Se detectaron efectos significativos $(\mathrm{p}<0.05)$ mediante el análisis de varianza (ANOVA) utilizando el software STATISTICA (v.10 StatSoft, Tulsa, Oklahoma, EE.UU.). Se realizaron comparaciones de medias con la prueba de Tukey's $(\alpha=0.05)$. Cada determinación se realizó al menos tres veces. Los valores se expresaron como media \pm desviación estándar.

\section{RESULTADOS Y DISCUSIÓN Actividad proteolítica}

La actividad enzimática de las proteasas de $B$. karatas y $B$. pinguin proteasas fue de 10.0 y $22.83 \mathrm{U} / \mathrm{mg}$ de proteína, respectivamente. Estos resultados confirmaron que las proteasas aisladas estaban activas, aunque las diferencias en las actividades catalíticas de las endopeptidasas dependen de su estructura y las diferencias genéticas de cada especie (Headon \& Walsh, 1994).

\section{Inhibición de hemólisis oxidativa (IHO)}

En la Tabla I se muestran los resultados de la capacidad de IHO de hidrolizados proteícos. Se encontró que la IHO de todos los hidrolizados fue dependiente del tiempo en el cual se obtuvieron y del tipo de proteasa usada para la hidrólisis de las proteínas evaluadas. La IOH fue alta (66.90-94.36\%) en todos los hidrolizados obtenidos. El efecto del tiempo se debe a que las proteasas a $120 \mathrm{~min}$, causaron seguramente un mayor porcentaje de hidrólisis proteíco. Se ha reportado que a mayor grado de hidrólisis, mayor es la variabilidad en tamaño de PB (Meza-Espinoza et al., 2017); así, su funcionalidad o bioactividad puede aumentar debido a que se pueden presentar efectos sinérgicos en la eliminación de los radicales libres y por ende ocurra una mayor actividad de IHO (Klompong, Benjakul, Kantachote \& Shahidi, 2007). Las diferencias en la IHO dependiente de las proteasas extraídas por especie vegetal y sustratos usados $(\mathrm{p}<0.05)$, se atribuye a la especificidad de cada proteasa, por ende, cada una puede producir hidrolizados con diferentes tamaños de péptidos con diferente composición de aminoácidos (Vioque et al., 2006). Klompong, Benjakul, Kantachote \& Shahidi (2007), mencionaron que el sustrato

\begin{tabular}{|c|c|c|c|c|}
\hline \multirow{2}{*}{ Proteasas } & \multirow{2}{*}{ Proteína } & \multicolumn{3}{|c|}{ Tiempo de hidrólisis (min) } \\
\hline & & 30 & 60 & 120 \\
\hline \multirow{3}{*}{ 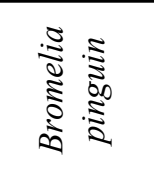 } & Ovoalbúmina & $76.76 \pm 1.72 b X$ & $82.39 \pm 1.72 \mathrm{aW}$ & $83.09 \pm 1.17 \mathrm{aY}$ \\
\hline & Leche & $92.25 \pm 2.72 \mathrm{aW}$ & $92.95 \pm 4.59 \mathrm{aV}$ & $94.36 \pm 1.15 \mathrm{aV}$ \\
\hline & Soya & $78.87 \pm 1.15 \mathrm{cX}$ & $83.80 \pm 0.57 \mathrm{aW}$ & $85.21 \pm 0.57 \mathrm{aX}$ \\
\hline \multirow{3}{*}{ 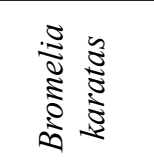 } & Ovoalbúmina & $69.01 \pm 2.29 \mathrm{cY}$ & $78.87 \pm 1.157 \mathrm{bX}$ & $90.01 \pm 1.15 \mathrm{aW}$ \\
\hline & Leche & $69.71 \pm 1.15 \mathrm{cY}$ & $74.64 \pm 1.15 \mathrm{bY}$ & $83.09 \pm 3.449 \mathrm{aY}$ \\
\hline & Soya & $44.36 \pm 6.32 \mathrm{bZ}$ & $67.60 \pm 3.44 \mathrm{aZ}$ & $66.90 \pm 2.87 \mathrm{aZ}$ \\
\hline
\end{tabular}

Los valores son la media de tres réplicas $(n=3) \pm$ desviación estándar. Letras diferentes $(a, b, c)$ por fila indican diferencia significativa ( $<<0.05)$ entre tiempo de hidrólisis, mientras que letras diferentes por columna $(\mathrm{V}, \mathrm{W}, \mathrm{X}, \mathrm{y} \mathrm{Z})$, indican diferencia significativa $(\mathrm{p}<0.05)$ entre sustratos proteícos y especie vegetal a un mismo tiempo de hidrólisis.

Tabla I. Inhibición hemolítica oxidativa (\%) por efecto de hidrolizados proteícos de ovoalbúmina, leche y soya obtenidos a diferentes tiempos usando proteasas de Bromelia pinguin y Bromelia karatas. 
y tipo de proteasas utilizadas para la hidrólisis de proteínas juegan un papel muy importante en la determinación del poder biológico de los hidrolizados. Por su parte, $\mathrm{Wu}$, Chen \& Shiau (2003) concluyeron que las diferencias en la actividad biológica de los hidrolizados de proteínas se atribuyen a la composición específica de péptido/aminoácido. Aguilar-Toalá et al. (2017) reportaron que extractos crudos de péptidos de leche fermentada con especies Lactobacillus plantarum presentaron una actividad de IHO de 36.65-74.45\%; lo cual evidencia que los hidrolizados obtenidos en este experimento presentaron mayor IHO.

La capacidad de IHO también se observó cuando se usaron fracciones peptídicas (Tabla II). La IHO fue estadísticamente mayor $(\mathrm{p}<0.05)$ cuando se usaron las fracciones $\leq 5 \mathrm{y} \leq 1 \mathrm{kDa}$ (91.76 y $90.50 \%)$ obtenidas de la hidrólisis de proteína de leche u ovoalbúmina $(95.04$ y $98.19 \%$ ) con proteasas de $B$. pinguin y $B$. karatas, respectivamente. Aguilar-Toalá et al. (2017), reportaron que fracciones de péptidos obtenidos de leches fermentadas con tamaño $<10 \mathrm{kDa}$ mostraron una IHO de 40.68-58.84\%, mientras que fracciones con tamaño $<3 \mathrm{kDa}$ tuvieron una IHO de 22.50-36.65\%. Zheng, Dong, Su, Zhao \& Zhao (2016) midieron un 90\% de reducción de la hemólisis de eritrocitos humanos cuando se incrementó la concentración de $0.1 \mathrm{mM}$ a $5 \mathrm{mM}$ de dipéptidos. Los autores reportaron que los dipéptidos en el orden de: Trp-Gly $>$ Tyr-Gly $>$ Met-Gly $>$ CysGly, tuvieron un efecto protector en los eritrocitos, sugiriendo que los dipéptidos podrían protegerlos contra daño oxidativo inducido, principalmente por actuar como secuestradores de radicales libres. Esta evidencia sugiere que además del tamaño de los péptidos, la diferencia en la composición de aminoácidos y su concentración influyeron en la IHO. Xiong (2010) por su parte reportó que la actividad antioxidante se asocia principalmente a la presencia de aminoácidos como cisteína, metionina, tirosina, fenilalanina, triptófano, prolina, lisina entre otros; que permiten una buena acción antiradical y quelante, debido a que estos aminoácidos son capaces de donar electrones o formar complejos con iones metálicos. Esto significa que la actividad antioxidante encontrada en este experimento, dependió probablemente más de la estructura del péptido, que de su tamaño.

La descomposición del AAPH (compuesto usado para medir la IHO) genera radicales peroxilo que inician el proceso peroxidativo, generando a la vez otros radicales libres para inducir la oxidación de los ácidos grasos y proteínas, ocasionando un daño sobre la organización de los eritrocitos y conduciendo eventualmente a lisis de la membrana (Pannangpetch et al., 2007). Actualmente no se conocen del todo los posibles mecanismos subyacentes a la IHO de los extractos y fracciones peptídicas solubles en agua, debido a que los estudios son escasos. Sin embargo, varios estudios han demostrado que aminoácidos, péptidos e hidrolizados crudos, exhiben protección biológica por mecanismos diferentes, como donación o aceptación de electrones y quelación de metales (Saidi, Deratani, Belleville \& Amar, 2014); por lo tanto, es posible que los péptidos bioactivos presentes en los hidrolizados y fracciones peptídicas evaluadas en este experimento, podrían ser responsables de la prevención de la hemólisis mediante la capacidad de neutralizar los radicales peroxilo generados en la reacción de medición y posiblemente, que los péptidos tienen la capacidad de inhibir la peroxidación lipídica (Abdel-Hamid, Otte, De Gobba, Osman \& Hamad, 2017; Kumar, Chatli, Singh, Mehta \& Kumar, 2016; Liu, Jin, Lin, Jones \& Chen, 2015); no obstante, se requieren mayores estudios para elucidar que la capacidad de IHO de los hidrolizados y cada fracción, está en función de la composición química de cada uno de ellos.

\section{Actividad antimicrobiana}

No se encontró inhibición de los patógenos evaluados cuando se trataron con los hidrolizados (Datos no mostrados). Sin

\begin{tabular}{|c|c|c|c|c|c|}
\hline \multirow{2}{*}{ Proteasas } & \multirow{2}{*}{ Proteína } & \multicolumn{4}{|c|}{ Fracciones peptídicas } \\
\hline & & $\leq 30 \mathrm{kDa}$ & $\leq 10 \mathrm{kDa}$ & $\leq 5 \mathrm{kDa}$ & $\leq 1 \mathrm{kDa}$ \\
\hline \multirow{3}{*}{ 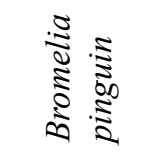 } & Ovoalbúmina & $78.17 \pm 1.72 \mathrm{aX}$ & $82.69 \pm 2.96 \mathrm{aW}$ & $79.51 \pm 3.61 \mathrm{aY}$ & $79.20 \pm 2.01 \mathrm{aY}$ \\
\hline & Leche & $89.27 \pm 3.76 \mathrm{aV}$ & $74.90 \pm 1.52 b Y$ & $91.76 \pm 2.02 \mathrm{aW}$ & $90.50 \pm 2.03 \mathrm{aW}$ \\
\hline & Soya & $83.85 \pm 3.45 \mathrm{bW}$ & $79.55 \pm 1.32 \mathrm{cX}$ & $87.85 \pm 2.92 \mathrm{aX}$ & $83.91 \pm 2.85 \mathrm{bX}$ \\
\hline \multirow{3}{*}{ 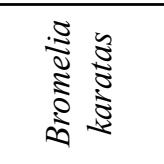 } & Ovoalbúmina & $72.37 \pm 1.88 \mathrm{dY}$ & $83.93 \pm 1.51 \mathrm{cW}$ & $95.04 \pm 0.31 \mathrm{bV}$ & $98.19 \pm 0.20 \mathrm{aV}$ \\
\hline & Leche & $89.73 \pm 0.40 \mathrm{aV}$ & $89.46 \pm 1.12 \mathrm{aV}$ & $89.60 \pm 1.11 \mathrm{aW}$ & $78.26 \pm 0.67 \mathrm{bY}$ \\
\hline & Soya & $85.48 \pm 1.57 \mathrm{bW}$ & $78.54 \pm 1.34 \mathrm{cX}$ & $66.19 \pm 1.61 \mathrm{dZ}$ & $89.42 \pm 1.18 \mathrm{aW}$ \\
\hline
\end{tabular}

Los valores son la media de tres réplicas $(n=3) \pm$ desviación estándar. Letras diferentes $(a, b, c)$ por fila indican diferencia significativa $(\mathrm{p}<0.05)$ entre los tamaños de las fracciones, mientras que letras diferentes $(\mathrm{V}, \mathrm{W}, \mathrm{X}, \mathrm{y} \mathrm{Z})$ por columna, indican diferencia significativa $(\mathrm{p}<0.05)$ entre sustratos proteícos y especie vegetal en un mismo tamaño de fracción.

Tabla Il. Inhibición hemolítica oxidativa (\%) por efecto de fracciones peptídicas obtenidos de hidrolizados proteícos (ovoalbúmina, leche y soya) usando proteasas de Bromelia pinguin y Bromelia karatas. 
embargo, algunas de las fracciones peptídicas tuvieron efecto significativo $(\mathrm{p}<0.05)$ contra E. coli, S. aureus, L. innocua, $S$. Typhimurium y $S$. Choleraesuis.

En la Tabla III se muestra la actividad antimicrobiana de las fracciones peptídicas obtenidas con proteasas de $B$. pinguin. Todas las fracciones peptídicas obtenidas de la hidrólisis del concentrado de soya, tuvieron mayor inhibición para $S$. Typhimurium; aunque la fracción de $\leq 5 \mathrm{kDa}$ presentó la mayor inhibición (20.59\%), las fracciones peptídicas de ovoalbúmina y leche práticamente no tuvieron inhibición contra este patógeno. Las fracciones peptídicas de $\leq 5, \leq 10 \mathrm{y} \leq 30 \mathrm{kDa}$, provenientes de la hidrólisis de leche, tuvieron la mayor inhibición para $S$. Choleraesuis, E. coli, L. innocua y $S$. aureus; y el microorganismo mayormente inhibido fue L. innocua con $23.79 \%$ de inhibición con la fracción peptídica de $\leq 5 \mathrm{kDa}$, mientras que $S$. Choleraesuis tuvo la menor inhibición $(4.32 \%)$ con la fracción de $30 \mathrm{kDa}$. Aguilar-Toalá et al.,(2017) encontraron valores de supervivencia de 54.54-92.38\% (7.62-45.46\% de inhibición) en el mismo tipo de patógenos, que fueron tratados con fracciones peptídicas de $<3$ y $<3-10 \mathrm{kDa}$ obtenidas de leches fermentadas con Lactobacillus plantarum. Esos mismos autores encontraron una mayor inhibición de E. coli (45.50\%) y L. innocua (31.44\%); mientras que $S$. Choleraesuis fue la menos inhibida (7.62\%). La actividad antimicrobiana está relacionada con el tamaño de los péptidos, algunos reportes mencionan que la presencia de péptidos con 5-7 $\mathrm{kDa}$ y $<30 \mathrm{kDa}$ tienen la mayor actividad inhibitoria de microorganismos (Sadredinamin, Mehrnejad, Hosseini \& Doustdar, 2016; Dziuba \& Dziuba, 2014), el cual coincide con algunos de nuestros resultados.

\begin{tabular}{|c|c|c|c|c|}
\hline \multirow{2}{*}{ Patógeno } & \multirow{2}{*}{$\begin{array}{c}\text { Tamaño de } \\
\text { péptidos }\end{array}$} & Ovoalbúmina & Leche & Soya \\
\hline & & \multicolumn{3}{|c|}{ Inhibición (\%) } \\
\hline Salmonella Typhimurium & \multirow{3}{*}{$\leq 1 \mathrm{kDa}$} & $1.40 \pm 0.10 \mathrm{c}$ & $10.02 \pm 0.07 \mathrm{~b}$ & $14.25 \pm 0.61 \mathrm{a}$ \\
\hline Escherichia coli & & $10.93 \pm 0.31 \mathrm{a}$ & $9.13 \pm 0.35 \mathrm{a}$ & $4.63 \pm 0.03 b$ \\
\hline Listeria innocua & & $12.49 \pm 0.2 \mathrm{c}$ & $18.86 \pm 0.05 a$ & $15.45 \pm 0.18 \mathrm{~b}$ \\
\hline Salmonella Typhimurium & \multirow[b]{3}{*}{$\leq 5 \mathrm{kDa}$} & - & - & $20.59 \pm 0.55 c$ \\
\hline Salmonella Choleraesuis & & - & $6.02 \pm 0.14 \mathrm{a}$ & $0.32 \pm 0.01 b$ \\
\hline Escherichia coli & & $6.08 \pm 0.01 \mathrm{c}$ & $20.69 \pm 0.32 \mathrm{a}$ & $9.08 \pm 0.14 b$ \\
\hline Salmonella Typhimurium & \multirow{5}{*}{$\leq 10 \mathrm{kDa}$} & - & $9.28 \pm 0.12 b$ & $12.46 \pm 0.34 \mathrm{a}$ \\
\hline Salmonella Choleraesuis & & - & $9.89 \pm 0.36 \mathrm{a}$ & $0.38 \pm 0.27 b$ \\
\hline Escherichia coli & & $4.06 \pm 0.09 c$ & $15.99 \pm 0.22 \mathrm{a}$ & $11.50 \pm 0.27 b$ \\
\hline Listeria innocua & & $13.76 \pm 0.09 b$ & $23.25 \pm 0.24 a$ & $10.31 \pm 0.10 \mathrm{c}$ \\
\hline Staphylococcus aureus & & $7.48 \pm 0.3 b$ & $10.68 \pm 0.32 \mathrm{a}$ & $1.57 \pm 0.14 \mathrm{c}$ \\
\hline Salmonella Typhimurium & \multirow{2}{*}{$\leq 30 \mathrm{kDa}$} & - & $15.42 \pm 0.02 b$ & $16.40 \pm 0.09 a$ \\
\hline Salmonella Choleraesuis & & $2.68 \pm 0.04 b$ & $4.32 \pm 0.01 \mathrm{a}$ & - \\
\hline
\end{tabular}

Los valores son la media de tres réplicas $(n=3) \pm$ desviación estándar. Letras diferentes $(\mathrm{a}, \mathrm{b}, \mathrm{c})$ por fila indican diferencia significativa $(\mathrm{p}<0.05)$ para cada una de las fracciones y para cada patógeno. $(-)=$ Sin inhibición.

Tabla III. Porcentaje de inhibición de bacterias patógenas por efecto de fracciones peptídicas obtenidas de hidrolizados proteícos (ovoalbúmina, leche y soya) usando proteasas de Bromelia pinguin. 
Hubo una menor inhibición antimicrobiana de las fracciones peptídicas provenientes de la hidrólisis de los sustratos proteícos con $B$. karatas (Tabla IV). S. Thyphimurium no fue inhibida por la mayoría de las fracciones derivadas de los tres sustratos; sólo se obsevó una inhibición de $3.48 \%$ con la fracción peptídica de $\leq 30 \mathrm{kDa}$ obtenida del hidrolizado de ovalbúmina. Así mismo, $S$. Choleraesuis, fue poco inhibida y solo las fracciones peptídicas obtenidas de la hidrólisis de leche presentaron una inhibición de 3.56 a $8.56 \%$. Al patógeno E. coli ninguno de los tratamientos lo inhibió. Mientras que a L. innocua todas las fracciones peptídicas de leche y soya le causaron inhibición y la inhibición más alta (18.43\%), se midió con la fracción peptídica de $\leq 1 \mathrm{kDa}$ obtenida del hidrolizado de soya. Finalmente, la fracción peptídica de $\leq 1 \mathrm{kDa}$, separada del hidrolizado de ovalbúmina fue la que inhibió a $S$. aureus en una proporción de $11.46 \%$.

Es conocido que las bacterias gram positivas poseen en su pared celular una capa gruesa de peptidoglucano y ácidos teicoicos con mayor resistencia intrínseca a ser inhibidas que las bacterias gram negativas (Chopra \& Greenwood, 2001). Sin embargo, en este experimento, la variabilidad en la actividad antimicrobiana encontrada se atribuye principalmente a los diferentes mecanismos de acción de los AMPs, que dependen de su tamaño, composición en aminoácidos, y características fisicoquímicas (Maria-Neto, de Almeida, Macedo \& Franco, 2015; Ghosh \& Haldar, 2015; Reinhardt \& Neundorf, 2016), ya que no hubo una inhibición concluyente entre microorganismos

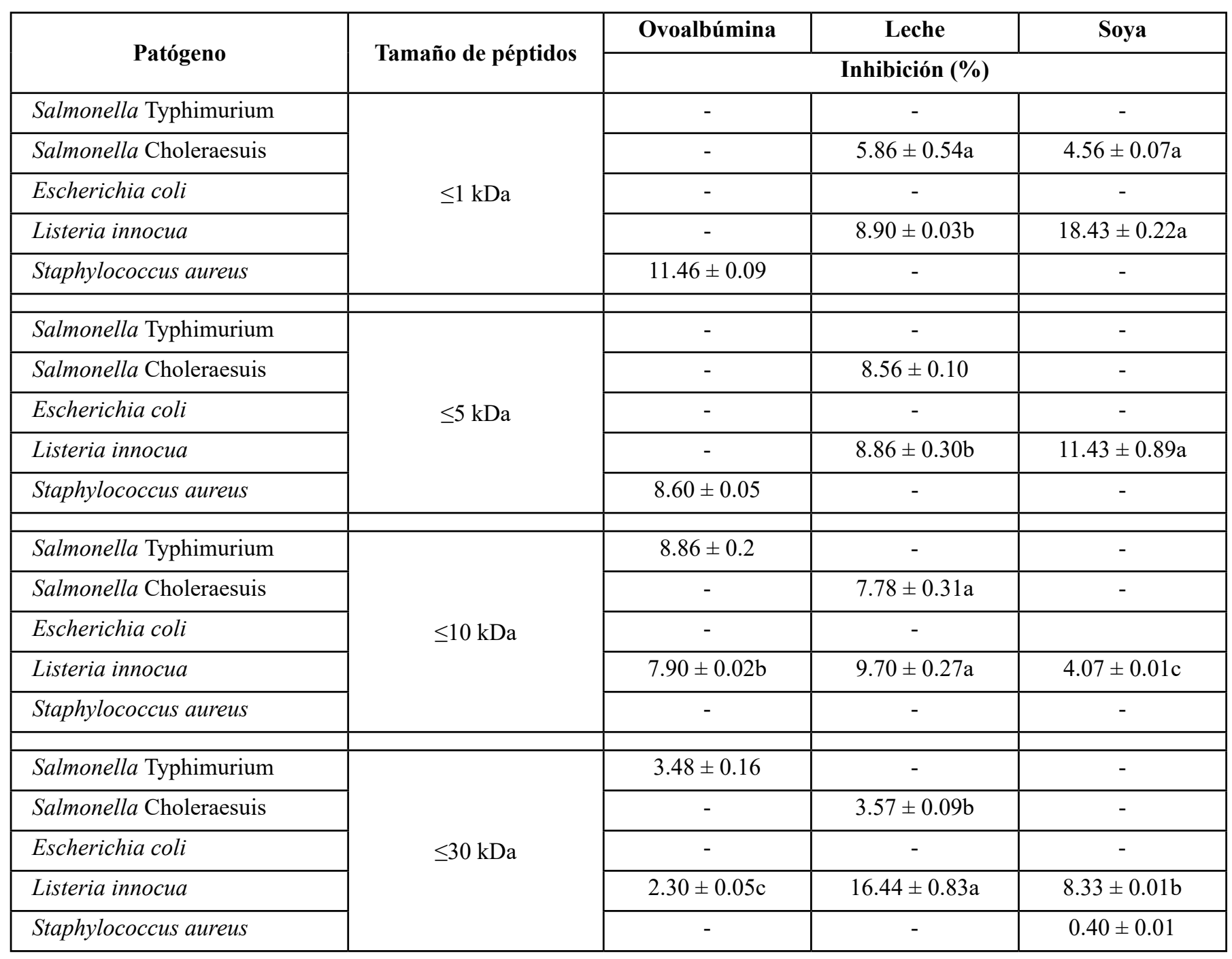

Los valores son la media de tres réplicas $(n=3) \pm$ desviación estándar. Letras diferentes $(a, b, c)$ por fila indican diferencia significativa $(p<0.05)$ para cada una de las fracciones y para cada patógeno. $(-)=$ Sin inhibición.

Tabla IV. Porcentaje de inhibición de bacterias patógenas por efecto de fracciones peptídicas obtenidas de hidrolizados proteícos (ovoalbúmina, leche y soya) usando proteasas de Bromelia karatas. 
gram negativos o gram positivos. Se ha reportado la naturaleza catiónica de los AMPs, éstos son atraídos por las cargas negativas de la membrana debido a la presencia del ácido lipoteicoico y lipopolisacáridos de los microorganimos, ocurriendo una interacción altamente selectiva, generando poros que causan la liberación de compuestos intracelulares ocasionando la muerte celular (Scott, Gold \& Hancock, 1999). Sin embargo, la toxicidad de los AMPs contra células procariontes sigue siendo un tema importante y tiene que ser investigado debido a la diversidad de péptidos que se pueden generar, dependiendo de su origen y las diferentes estructuras microbianas en las que pueden actuar, como bacterias gram negativas o gram positivas (Wang et al., 2009; Huang et al., 2010). Aunque para la mayoría de los AMPs se describen procesos de permeabilización de la membrana, también pueden actuar utilizando otros mecanismos. Después de entrar en las células patógenas, estos AMPs alcanzan moléculas intracelulares, lo que lleva a la inhibición de la síntesis de la pared celular (Brötz, Bierbaum, Leopold, Reynolds \& Sahl, 1998), la inactivación de enzimas (Kavanagh \& Dowd, 2004) o interferencia en la síntesis de DNA, RNA y síntesis de proteínas (Vineethkumar, Asha, Shyla \& George, 2017; Zhang et al., 2017).

Por otro lado, el efecto del tipo de proteasas usadas para obtener péptidos con acción antimicrobiana, se atribuye a diferencias en las actividades catalíticas de cada endopeptidasa por cada sustrato (Vioque et al., 2006), como se mencionó anteriormente. Cada proteasa usada en este experimento posiblemente produjo péptidos con diferente tamaño y composición que a su vez tuvieron diferente acción antimicrobiana (Klompong, Benjakul, Kantachote \& Shahidi, 2007; Wu, Chen \& Shiau, 2003). Así, se puede deducir que las proteasas de B. karatas son menos efectivas para producir AMPs que las proteasas de B. pinguin; aunque es importante continuar con más investigaciones para soportar esta hipótesis.

\section{CONCLUSIONES}

En el presente estudio se encontró una alta inhibición de hemólisis oxidativa tanto de hidrolizados como de fracciones peptídicas $(<1 \mathrm{kDa})$, obtenidos a partir de la hidrólisis de proteína de leche y/o ovoalbúmina, usando ambas proteasas. A pesar de que los hidrolizados no presentaron actividad antimicrobiana, las fracciones peptídicas obtenidas de los hidrolizados de leche con proteasas de B. pinguin registraron inhibición contra E. coli y L. innocua, aunque la inhibición fue baja. Los hidrolizados o fracciones peptídicas derivados de la hidrólisis de ovalbúmina, leche y soya con proteasas extraídas de los frutos de $B$. pinguin y $B$. karatas, tienen un valioso potencial para generar PB con actividad antioxidante. Sin embargo, otros estudios son necesarios como la identificación de secuencias de aminoácidos de las fracciones peptídicas, determinar su mecanismo preciso de acción y validar su actividad biológica in vivo.

\section{Agradecimientos}

Los autores agradecen al Tecnológico Nacional de México por el financiamiento otorgado en el proyecto con clave 5613.15-P y al Consejo Nacional de Ciencia y Tecnología (CONACYT) por la beca otorgada a la co-autora Libier Meza Espinoza.

\section{Conflicto de interés}

Los autores declaran que no hay conflicto de interés.

\section{Referencias}

Abdel-Hamid, M., Otte, J., De Gobba, C., Osman, A. \& Hamad, E. (2017). Angiotensin I-converting enzyme inhibitory activity and antioxidant capacity of bioactive peptides derived from enzymatic hydrolysis of buffalo milk proteins. Int. Dairy J., 66, 91-98. DOI: 10.1016/j.idairyj.2016.11.006.

Aguilar-Toalá, J. E., Santiago-López, L., Peres, C. M., Peres, C., García, H. S., Vallejo-Córdoba, B., González-Córdoba A.F. \& Hernández-Mendoza, A. (2017). Assessment of multifunctional activity of bioactive peptides derived from fermented milk by specific Lactobacillus plantarum strains. J. Dairy Sci., 100, 65-75. DOI: 10.3168/jds.2016-11846.

Bradford, M. M. (1976). A rapid and sensitive method for the quantitation of microgram quantities of protein utilizing the principle of protein-dye binding. Anal. Biochem. 72: 248-254.

Brötz, H., Bierbaum, G., Leopold, K., Reynolds, P. E. \& Sahl, H. G. (1998). The lantibiotic mersacidin inhibits peptidoglycan synthesis by targeting lipid II. Antimicrob. Agents Chemother., 42, 154-160.

Cho, M. J., Unklesbay, N., Hsieh, F. H. \& Clarke, A. D. (2004). Hydrophobicity of bitter peptides from soy protein hydrolysates. J. Agric. Food Chem., 52, 5895-5901. DOI: 10.1021/jf0495035.

Chopra, I. \& Greenwood, D. (2001). Antibacterial Agents: Basis of Action. En: Battista, J. (Ed.), Encyclopedia of life sciences (pp. 1-8). Hoboken, New Jersey: Wiley, Ltd.

Dziuba, B. \& Dziuba, M. (2014). New milk protein-derived peptides with potential antimicrobial activity: An approach based on bioinformatic studies. Int. J. Mol. Sci., 15, 14531-14545. DOI:10.3390/ijms150814531.

Eloff, J. N. (1998). A sensitive and quick microplate method to determine the minimal inhibitory concentration of plant extracts for bacteria. Planta Med., 64, 711-713. DOI: $10.1055 / \mathrm{s}-2006-957563$.

Ghosh, C. \& Haldar, J. (2015). Membrane-active small molecules: designs inspired by antimicrobial peptides. Chem. Med. Chem., 10, 1606-1624. DOI: 10.1002/cmdc.201500299.

Headon, D.R. \& Walsh, G. (1994). The industrial production of enzymes. Biotechnol. Adv., 12, 635-646. DOI: 10.1016/07349750(94)90004-3.

Huang, J. F., Xu, Y. M., Hao, D. M., Huang, Y. B., Liu, Y. \& Chen, Y. (2010). Structure-guided de novo design of $\alpha$-helical antimicrobial peptide with enhanced specificity. Pure Appl. Chem., 82, 243-257. DOI: 10.1351/PAC-CON-09-01-12. 
Kavanagh, K. \& Dowd, S. (2004). Histatins: antimicrobial peptides with therapeutic potential.J. Pharm. Pharmacol., 56, 285-289. DOI: $10.1211 / 0022357022971$.

Klompong, V., Benjakul, S., Kantachote, D., \& Shahidi, F. (2007). Antioxidative activity and functional properties of protein hydrolysate of yellow stripe trevally (Selaroides leptolepis) as influenced by the degree of hydrolysis and enzyme type. Food Chem., 102, 1317-1327. DOI: 10.1016/j. foodchem.2006.07.016.

Kumar, D., Chatli, M. K., Singh, R., Mehta, N. \& Kumar, P. (2016). Antioxidant and antimicrobial activity of camel milk casein hydrolysates and its fractions. Small Rumin. Res., 139, 20-25. DOI: 10.1016/j.smallrumres.2016.05.002.

Liu, J., Jin, Y., Lin, S., Jones, G. S. \& Chen, F. (2015). Purification and identification of novel antioxidant peptides from egg white protein and their antioxidant activities. Food Chem., 175, 258266. DOI: 10.1016/j.foodchem.2014.11.142.

Maria-Neto, S., de Almeida, K. C., Macedo, M. L. R. \& Franco, O. L. (2015). Understanding bacterial resistance to antimicrobial peptides: From the surface to deep inside. Biochim. Biophys. Acta., 1848,3078-3088. DOI: 10.1016/j.bbamem.2015.02.017.

Meza-Espinoza, L., Vivar-Vera, M.A., García-Magaña, M.L., SáyagoAyerdi, S. G., Chacón-López, A., Becerra-Verdín, E. M. \& Montalvo-González, E. (2017). Enzyme activity and partial characterization of proteases obtained from Bromelia karatas fruit and compared with Bromelia pinguin proteases. Food Sci. Biotechnol. (In press) DOI: 10.1007/s10068-017-0244-6.

Moreno-Hernández, J. M., Hernández-Mancillas, X. D., Navarrete, E. L. C., Mazorra-Manzano, M. Á., Osuna-Ruiz, I., Rodríguez-Tirado, V.A. \& Salazar-Leyva, J.A. (2017). Partial characterization of the proteolytic properties of an enzymatic extract from "Aguama" Bromelia pinguin L. Fruit grown in Mexico. Appl. Biochem. Biotechnol., 182, 181-196. DOI: 10.1007/s12010-016-2319-x.

Natalucci, C. L., Brullo, A., López, L. M. I., Hilal, R.M. \& Caffini, N. O. (1996). Macrodontin, a new protease isolated from fruits of Pseudananas macrodontes (Morr.) Harms (Bromeliaceae). J. Food Biochem., 19, 443-454. DOI: 10.1111/j.1745-4514.1995. tb00547.x

Pannangpetch, P., Laupattarakasem, P., Kukongviriyapan, V., Kukongviriyapan, U., Kongyingyoes, B. \& Aromdee, C. (2007). Antioxidant activity and protective effect against oxidative hemolysis of Clinacanthus nutans (Burm. f) Lindau. Songklanakarin J. Sci. Technol., 29, 1-9.

Przybylski, R., Firdaous, L., Châtaigné, G., Dhulster, P. \& Nedjar, N. (2016). Production of an antimicrobial peptide derived from slaughterhouse by-product and its potential application on meat as preservative. Food Chem., 211, 306-313. DOI: 10.1016/j. foodchem.2016.05.074

Reinhardt, A. \& Neundorf, I. (2016). Design and application of antimicrobial peptide conjugates. Int. J. Mol. Sci., 17(5), 701721. DOI: 10.3390/ijms17050701.
Sadredinamin, M., Mehrnejad, F., Hosseini, P. \& Doustdar, F. (2016). Antimicrobial Peptides (AMPs). Novelty Biomed., 4, 70-76.

Saidi, S., Deratani, A., Belleville, M. P. \& Amar, R. B. (2014). Antioxidant properties of peptide fractions from tuna dark muscle protein by-product hydrolysate produced by membrane fractionation process. Food Res. Int., 65, 329-336. DOI: 10.1016/j.foodres.2014.09.023

Scott, M. G., Gold, M. R. \& Hancock, R. E. (1999). Interaction of cationic peptides with lipoteichoic acid and gram-positive bacteria. Infect. Immun., 67, 6445-6453.

Sila, A. \& Bougatef, A. (2016). Antioxidant peptides from marine by-products: isolation, identification and application in food systems a review. J. Funct. Foods, 21, 10-26. DOI: 10.1016/j. jff.2015.11.007

Takebayashi, J., Chen, J. \& Tai, A. (2010). A Method for Evaluation of antioxidant activity based on inhibition of free radical-induced rrythrocyte hemolysis. En: Armstrong D. (Ed.), Advanced Protocols in Oxidative Stress II. Methods in Molecular Biology (Methods and Protocols) (pp.287-296). Totowa, NJ, USA: Editorial Humana Press, Springer.

Vineethkumar, T. V., Asha, R., Shyla, G. \& George, S. (2017). Posttranslationally modified frog skin-derived antimicrobial peptides are effective against Aeromonas sobria. Microb. Pathog., 104, 287-288. DOI: 10.1016/j.micpath.2017.01.052

Vioque, J., Predoche, J., Yust, M. M., Lqari, H., Megías, C., GirónCalle, J., Aliaz, M. \& Millán, F. (2006). Peptídeos bioativos em proteínas vegetais de reserva. Rio de Janeiro, Brasil: Brazilian Journal of Food Technology III JIPCA, 1:99-102.

Wang, P., Bang, J. K., Kim, H. J., Kim, J. K., Kim, Y. \& Shin, S. Y. (2009). Antimicrobial specificity and mechanism of action of disulfide-removed linear analogs of the plant-derived Cys-rich antimicrobial peptide Ib-AMP1. Peptides, 30, 2144-2149. DOI: 10.1016/j.peptides.2009.09.020

Wu, H. C., Chen, H. M. \& Shiau, C. Y. (2003). Free amino acids and peptides as related to antioxidant properties in protein hydrolysates of mackerel (Scomber austriasicus). Food Res. Int., 36(9), 949-957. DOI: 10.1016/S0963-9969(03)00104-2.

Xiong, Y. L. (2010). Functions of biologically active proteins and peptides: Antioxidant peptides. En: Y., Mine, E., Li-Chan \& Jiang, B. (Ed.). Bioactive Proteins and Peptides as Functional Foods and Nutraceuticals (pp. 29-42). Iowa, USA: IFT Press, Wiley-Blackwell.

Zhang, F., Cui, X., Fu, Y., Zhang, J., Zhou, Y., Sun, Y., Wang, X., Li, Y., Liu, Q. \& Chen, T. (2017). Antimicrobial activity and mechanism of the human milk-sourced peptide casein201. Biochem. Biophys. Res. Commun., 485, 698-704. DOI: 10.1016/j.bbrc.2017.02.108.

Zheng, L., Dong, H., Su, G., Zhao, Q. \& Zhao, M. (2016). Radical scavenging activities of Tyr-, Trp-, Cys-and Met-Gly and their protective effects against AAPH-induced oxidative damage in human erythrocytes. Food Chem., 197, 807-813. DOI: 10.1016/j.foodchem.2015.11.012. 